\title{
Aggregation of Titanium Dioxide Nanoparticles: Role of a Fulvic Acid
}

Rute F. Domingos ${ }^{1,}{ }^{*}$, Nathalie Tufenkji ${ }^{2}$, Kevin J. Wilkinson ${ }^{1}$

${ }^{1}$ Département de Chimie, Université de Montréal

C.P. 6128, succursale Centre-ville, Montréal QC, H3C 3J7, Canada

${ }^{2}$ Department of Chemical Engineering, McGill University 3610 University Street, Montreal QC, H3A 2B2, Canada

${ }^{*}$ Corresponding author

email: ri.ferreira.domingos@umontreal.ca

phone number: 514 343-6111 ext.: 4929

fax number: 514 343-7586 


\begin{abstract}
The increasing use of nanomaterials in consumer products has led to increased concerns about their potential environmental and health impacts. To better understand the transport, fate and behavior of nanoparticles in aquatic systems, it is essential to understand their interactions with different components of natural waters including natural organic matter over a broad range of physicochemical conditions. Fluorescence correlation spectroscopy was used to determine the diffusion coefficients of $\mathrm{TiO}_{2}$ nanoparticles having a nominal size of 5 nm. The effects of a various concentrations of the Suwannee River Fulvic Acid (SRFA) and the roles of $\mathrm{pH}$ and ionic strength were evaluated. Aggregation of the bare $\mathrm{TiO}_{2}$ nanoparticles increased for $\mathrm{pH}$ values near the zero point of charge. At any given $\mathrm{pH}$, an increase in ionic strength generally resulted in increased aggregation. Furthermore, conditions which favored adsorption of the SRFA resulted in less aggregation of the $\mathrm{TiO}_{2}$ nanoparticles, presumably due to increased steric repulsion. Under the conditions studied here, nanoparticle dispersions were often stable for environmentally relevant conditions of SRFA, $\mathrm{pH}$ and ionic strength, suggesting that in the natural environment, $\mathrm{TiO}_{2}$ dispersion might occur to a greater extent than expected.
\end{abstract}




\section{Introduction}

Research activities associated with nanotechnology have grown to the point where it is estimated that nanoparticle emissions to the environment will increase drastically in the near future (1). One widely used nanoparticle found in a large number of consumer products is titanium dioxide, $\mathrm{TiO}_{2}$. Nano- $\mathrm{TiO}_{2}$ is produced on a large scale for applications in photocatalysts, solar cells, biomaterials, memory devices and environmental catalysts (2-4). Given the small size, high mobility and high reactivity of the nano- $\mathrm{TiO}_{2}$ and its potential for release to the natural environment, it is important to evaluate the environmental risks associated with the mobility and persistence of this nanomaterial.

The aggregation of nanoparticles will strongly impact their reactivity (5), nanoparticlecellular interactions, and toxicity ( $)$. Furthermore, the state of aggregation of the nanoparticles in the natural environment is unlikely to be predicted from simple laboratory experiments that do not take into account the presence of natural organic matter (e.g., humic substances and microbial exudates) or environmentally relevant conditions of $\mathrm{pH}$ and ionic strength (1). For example, it is well known that humic substances can significantly modify the surface properties (e.g., electric charge, size, chemical nature of the exposed surface sites) of natural aquatic colloids, significantly influencing their transport, often due to increased electrostatic repulsion $(7,8)$. Only limited data are presently available on the aqueous stability of manufactured nanoparticles (fullerenes $(9,10)$, carbon nanotubes (11), alginate coated hematite (12) and iron oxides $(13,14))$ in the environment. In these studies, organic matter appeared either to increase the stability or solubility of the nanoparticles. Recently, $\mathrm{TiO}_{2}$ aggregation was 
measured in the absence (15) and presence of natural organic acids (16). Stable $\mathrm{TiO}_{2}$ suspensions predominated at $\mathrm{pH}$ values that were far from the point of zero charge, $\mathrm{pH}_{\mathrm{pzc}}$, and the presence of oxalic and adipic acid destabilized the nanoparticle suspensions. To our knowledge, no studies have followed $\mathrm{TiO}_{2}$ aggregation in the presence of the environmentally ubiquitous humic substances.

In this paper, diffusion coefficients were measured for $\mathrm{TiO}_{2}$ nanoparticles that were exposed to (simulated) natural conditions, i.e. humic substance content, $\mathrm{pH}$ and ionic strength. Diffusion coefficients were evaluated by fluorescence correlation spectroscopy (FCS) (17) at a relatively low concentration $\left(1.0 \mathrm{mg} \mathrm{L}^{-1}\right)$ of $\mathrm{TiO}_{2}$ nanoparticles. In spite of its unequaled sensitivity, two important limitations of FCS are that the particles must be fluorescent in order to be excited by one of the lasers on the system and the upper size limit of the aggregates is restricted by the size of the confocal volume $\left(c a .1 \mu \mathrm{m}^{3}\right)$. In this paper, the adsorption of natural fluorophores such as the humic substances or low concentrations of fluorescent probes were used to provide sufficient fluorescence intensity. In parallel, complementary observations of electrophoretic mobility (EPM) and transmission electron microscopy (TEM) were performed to provide information on the changing sizes or surface charge characteristics of the nanoparticles and their aggregates. 


\section{Experimental Section}

\section{Materials}

Small quantities (30 mg) of $\mathrm{TiO}_{2}$ (anatase, NanoStructured \& Amorphous Material, Inc) with a nominal size of $5 \mathrm{~nm}$ were added to Milli-Q water $\left(\mathrm{R}>18 \mathrm{M} \Omega \mathrm{cm}^{-1}, \mathrm{TOC}<2 \mu \mathrm{g}\right.$ $\left.\mathrm{C} \mathrm{L}^{-1}\right)$ to obtain a $1.0 \mathrm{~g} \mathrm{~L}^{-1}$ stock solution. A stock solution of the standard Suwannee River 1S101F fulvic acid (SRFA, International Humic Substances Society) was prepared from the freeze-dried solid by first equilibrating $130 \mathrm{mg} \mathrm{L}^{-1}$ for $24 \mathrm{~h}$ to ensure complete rehydration. Twenty four hours before measurements were to be performed, samples were prepared by dilution of the stock solutions into a prepared electrolyte solution (Milli-Q water with adjusted $\mathrm{pH}$ and ionic strength) to give a final $\mathrm{TiO}_{2}$ concentration of $1 \mathrm{mg} \mathrm{L}^{-1}$. Samples were prepared using a range of solution conditions: $\mathrm{pH} 2-8$, ionic strength $0.005-0.1 \mathrm{M}$ and fulvic acid concentrations $0.2-5.0 \mathrm{mg} \mathrm{L}^{-1}$. In absence of the SRFA, nanoparticles were labeled using $1 \times 10^{-8}$ M Rhodamine 6G (R6G) from Sigma-Aldrich (18), which has a known diffusion coefficient of $4.0 \times 10^{-10} \mathrm{~m}^{2} \mathrm{~s}^{-1}(19)$. For all experiments which examined the effect of the SRFA, the humic substances were sufficiently fluorescent that no additional label was required. Solution $\mathrm{pH}$ was measured using a Metrohm $744 \mathrm{pH}$ meter and a Metrohm Pt 1000 combination $\mathrm{pH}$ electrode, calibrated with standard $\mathrm{NBS}$ buffers. $\mathrm{NaNO}_{3}$ and $\mathrm{HNO}_{3}$ were trace select ultra grade (Fluka); analytical grade $\mathrm{NaOH}$ was purchased from ACP and MOPS from Sigma (min. 99.5\%). 


\section{Methods}

FCS measurements were performed with a Leica TCS SP5 laser scanning microscope using an argon ion laser for fluorescence excitation at 488 or $514 \mathrm{~nm}$. An avalanche photodiode detector was used to quantify fluorescence intensity fluctuations in a small volume $\left(c a .1 \mu \mathrm{m}^{3}\right)$ defined by the confocal optics of the instrument. The FCS technique is briefly described in the Supporting Information and in greater detail elsewhere $(17,20,21)$. Diffusion times of unknown components are measured and interpreted using an instrument defined autocorrelation function. Diffusion coefficients, $D$, are determined by calibrating the size and the shape of the confocal volume with Rhodamine 110 (R110, Fluka), which has a known diffusion coefficient of $4.4 \times 10^{-10} \mathrm{~m}^{2} \mathrm{~s}^{-1}$ (19). In this study, diffusion times were determined for $\mathrm{TiO}_{2}$ nanoparticles that were labeled by adsorption of small quantities of $\mathrm{R} 6 \mathrm{G}$ or SRFA. SRFA diffusion coefficients were determined independently for each experimental condition. To facilitate data presentation, results are presented with an indication of the average particle (or aggregate) hydrodynamic diameter, $d_{H}$, based upon the Stokes-Einstein equation:

$d_{H}=k T /(3 \pi \eta D)$

where $k$ is the Boltzmann constant, $T$ is the absolute temperature, and $\boldsymbol{\nabla}$ is the solution viscosity. We acknowledge that the assumption of a compact spherical particle required for this version of the equation may not be valid, especially when measuring aggregates.

Results are the means of triplicate runs or more performed on different days with freshly prepared samples. In each run, fifteen FCS measurements were made, with acquisition times of $80-150 \mathrm{sec}$. The raw data was interpreted using ISS Vista FCS software (version 
3.6_37). Standard deviations were determined from data of the replicate runs rather than the replicate measurements. Due to the temperature dependence of the diffusion coefficients, temperature was carefully measured and controlled $\left(23^{\circ} \mathrm{C}\right)$.

Electrophoretic mobility measurements were carried out using a Malvern Zetasizer Nano-ZS using disposable polystyrene cuvettes (Malvern, DTS1060) at $23^{\circ} \mathrm{C}$. Samples were prepared in an identical manner as for the FCS experiments. Results are the means of three replicate runs performed with freshly prepared samples on separate days. Each run is the mean of four to eight measurements. As above, standard deviations were determined from means obtained in the replicate runs rather than replicate measurements.

Transmission electron microscopy (Philips CM200 TEM) was used to determine the dimensions of the nanoparticles. TEM samples were prepared by placing a droplet of the $\mathrm{TiO}_{2}$ sample on a $\mathrm{Cu} 400$ mesh TEM grid that was covered by carbon film (Electron Microscopy Sciences) for five minutes. The diameters of 245 particles were evaluated using the Sigma Scan Pro 5.0 software.

\section{Results and Discussion}

Size of the disaggregated $\mathrm{TiO}_{2}$

Based upon the Stokes-Einstein equation (Equation 1), an average diameter of $3 \mathrm{~nm}$ could be estimated from FCS data for $1.0 \mathrm{mg} \mathrm{L}^{-1}$ of $\mathrm{TiO}_{2}$ nanoparticles in the presence of 1.0 mg L L ${ }^{-1}$ RFA $(I=0.01 \mathrm{M}, \mathrm{pH} 4.0)$, significantly smaller than the nominal size of $5 \mathrm{~nm}$ provided by NanoAmor. Under identical conditions, TEM images also indicated that this 
colloidal system was indeed completely disaggregated (Figure S1). In that case, a number average diameter of $3.2( \pm 0.4) \mathrm{nm}$ was obtained for 245 randomly analyzed particles. The difference in measured sizes among the different techniques could be due to a number of factors: (i) the techniques are measuring different diameters (number average (TEM), weight average (FCS), unknown (NanoAmor)); (ii) in the presence of SRFA, some disaggregation or dissolution of the $\mathrm{TiO}_{2}$ might be occurring (resulting in decreased diameters for the FCS and TEM) and (iii) the FCS calibration with R110 might result in a slight underestimation of particle size. With respect to this final point, diffusion coefficients that are used to calibrate the FCS confocal volume have recently been revised downward (19). Based on the historical values of the FCS calibration $\left(2.8 \times 10^{-10} \mathrm{~m}^{2} \mathrm{~s}^{-1}\right.$ for R6G (17)), diameters of $6 \mathrm{~nm}$ would have been found for the $\mathrm{TiO}_{2}$, more in line with manufacturers data. In any case, it should be noted that for all of the above systematic errors, none of the overall trends in the data would change; rather, all of the data would be shifted to slightly smaller $D$ values. Since the differences were within the errors of the techniques, the question of whether some limited $\mathrm{TiO}_{2}$ dissolution occurred could not be addressed thoroughly.

Another point that has the potential to influence measured particle sizes is that colloidal systems are highly dynamic: indeed, freshly prepared suspensions of nanoparticles could be observed to change with time (Figure S2). Aggregates grew less quickly for the solutions containing the fulvic acids, with the greatest stabilization occurring for the higher concentrations of SRFA. Furthermore, concentration was observed to be a critical factor influencing colloidal stability with higher concentrations observed to aggregate to a greater 
extent than the low concentrations employed here. Therefore, in order to facilitate comparison among the different sample conditions, all measurements discussed below were performed following a 24 hour "equilibration" of $1 \mathrm{mg} \mathrm{L}^{-1}$ of the $\mathrm{TiO}_{2}$ nanoparticles.

\section{Characterization of $\mathrm{TiO}_{2}$ nanoparticles in the absence of fulvic acid}

The presence of (low concentrations of) fluorescent label did not appear to have a significant effect on the particle surface characteristics: (i) no significant difference in electrophoretic mobility was observed in the absence $\left(-2.22 \pm 0.09 \mathrm{~m}^{2} \mathrm{~V}^{-1} \mathrm{~s}^{-1}\right)$ or presence ($2.15 \pm 0.08 \mathrm{~m}^{2} \mathrm{~V}^{-1} \mathrm{~s}^{-1}$ ) of $\mathrm{R} 6 \mathrm{G}$ and (ii) assuming $100 \%$ adsorption, concentrations of R6G would correspond to a surface coverage of only $c a .1 \%$. Diffusion coefficients of the labeled $\mathrm{TiO}_{2}$ nanoparticles were measured as a function of $\mathrm{pH}$ at different ionic strengths (Figure 1a). Stability generally decreased with increasing electrolyte concentration, consistent with a decrease in the thickness of the electrical double layer and a consequent decrease in repulsive electrostatic interactions among the $\mathrm{TiO}_{2}$ particles (calculated Debye layer thickness, $\kappa^{1}$, decreased from 4.3 at $5 \mathrm{mM}$ to $1.0 \mathrm{~nm}$ at $100 \mathrm{mM})$. At the lower $(\mathrm{pH}<4)$ and higher $(\mathrm{pH}>$ 6) $\mathrm{pH}$ values, average diameters were only slightly larger $(c a .10 \mathrm{~nm})$ than for a completely disaggregated system. Furthermore, for these $\mathrm{pH}$ values, the particles had larger absolute electrophoretic mobilities (Figure $1 \mathrm{~b}$ ) than those observed in the $\mathrm{pH}$ range of 4.5 to 5.2, which corresponded to the $\mathrm{pH}$ of zero point of charge $\left(\mathrm{pH}_{\mathrm{pzc}}\right)$ in good agreement with previously reported $\mathrm{pH}_{\mathrm{pzc}}$ values for anatase nanoparticles (22-25). For intermediate $\mathrm{pH}$ values that were near the $\mathrm{pH}_{\mathrm{pzc}}$, larger particle sizes (average diameters of $18-26 \mathrm{~nm}$ ) and significantly more 
polydispersity (larger error bars) were observed, strongly indicating that the $\mathrm{TiO}_{2}$ nanoparticles were aggregating.

\section{Characterization of the $\mathrm{TiO}_{2}$ nanoparticles in the presence of fulvic acid}

In order to determine diffusion coefficients of the $\mathrm{TiO}_{2}$ in presence of the fulvic acid, it is best to constrain the model fit of FCS data by measuring independently the diffusion coefficient of the fulvic acid, a parameter that is also dependent on the solution properties (e.g. $\mathrm{pH}$ and ionic strength) (26). At any given $\mathrm{pH}$, an increase in ionic strength from 0.005 to 0.1 $M$ resulted in a small decrease in the value of the diffusion coefficient of the SRFA, corresponding to a small $(<0.3 \mathrm{~nm})$ increase in its hydrodynamic diameter (Figure 2$)$. As above, an increase in ionic strength was interpreted to cause an increased screening of the charge on the fulvic acid molecule, which will decrease both the intramolecular and intermolecular repulsion (26). While decreased intramolecular repulsion will result in molecular compression (27) decreased intermolecular repulsion can result in increased aggregation (26). Similarly, protonation of the carboxylic sites on the SRFA with decreasing $\mathrm{pH}$ should result in a similar combination of the two opposing effects. Given that the fulvic acid is a fairly rigid molecule (28), the overall observed effect corresponds to a slight increase in hydrodynamic diameter (discussed in much greater detail in two previous studies $(26,29)$ ). For an ionic strength of $0.01 \mathrm{M}$, diffusion coefficients ranged from 2.7 to $3.3 \times 10^{-10} \mathrm{~m}^{2} \mathrm{~s}^{-1}$, corresponding to hydrodynamic diameters in the range of 1.3 to $1.6 \mathrm{~nm}$ and similar to those 
reported previously by FCS, nuclear magnetic resonance spectrometry and field flow fractionation $(26,29)$.

For solutions containing $1 \mathrm{mg} \mathrm{L}^{-1}$ of both $\mathrm{TiO}_{2}$ and SRFA, weight average hydrodynamic diameters of the $\mathrm{TiO}_{2}$ increased with $\mathrm{pH}$ (Figure 3). At $\mathrm{pH}$ 2, $\mathrm{TiO}_{2}$ appeared to be nearly disaggregated ( $d \approx 10 \mathrm{~nm}$, Figure $1 \mathrm{a}$ ), however, following the addition of $1 \mathrm{mg} \mathrm{L}$ ${ }^{1}$ of the SRFA, diameters decreased even further $(d \approx 3 \mathrm{~nm}$, Figure 3$)$. The observation of a decrease in hydrodynamic diameter in the presence of $1 \mathrm{mg} \mathrm{L}^{-1}$ of SRFA was also observed for all $\mathrm{pH}$ values up to $\mathrm{pH} 6.0$ (cf. Figure 1a and Figure 3). On the other hand, for $\mathrm{pH}$ values above the $\mathrm{pH}_{\mathrm{zpc}}$, colloidal suspensions were more disaggregated in the absence of $1 \mathrm{mg} \mathrm{L}^{-1}$ of SRFA than in its presence ( $c f$. Figure 1a and Figure 3; Figure 4). In these cases, high concentrations of SRFA were required both to completely disaggregate the $\mathrm{TiO}_{2}$ sample (Figure 4) and to stabilize the electrophoretic mobilities (Figure 5). Since electrophoretic mobilities of the $\mathrm{TiO}_{2}$ nanoparticles were significantly more negative in the presence of the fulvic acids ( $c f$. Figures 5 and $1 \mathrm{~b}$ ), the data suggests that in spite of their adsorption, the fulvic acids had only a limited stabilizing effect at the higher $\mathrm{pH}$ values. Since the fulvic acids and the $\mathrm{TiO}_{2}$ nanoparticles were both negatively charged at the higher $\mathrm{pH}$ values, we deduce that the increased aggregation was due to a bridging (flocculation) of the nanoparticles at the lower fulvic acid concentrations. Above $1 \mathrm{mg} \mathrm{L}^{-1}$ of added SRFA, hydrodynamic diameters decreased (Figure 4), likely attributed to an increasing steric stabilization of the particles.

In the absence of the fulvic acid, aggregation increased over the examined range of ionic strengths (5-100 mM, Figure 1a). In the presence of $1.0 \mathrm{mg} \mathrm{L}^{-1}$ of fulvic acid, changes in ionic 
strength had little effect at low $\mathrm{pH}(<5.0)$ since the diffusion coefficients corresponded, within experimental error, to single particles. In contrast, in the presence of $1 \mathrm{mg} \mathrm{L}^{-1}$ SRFA for $\mathrm{pH}$ values above the $\mathrm{pH}_{\mathrm{zpc}}$, a significant ionic strength effect was observed that was opposite to that observed above, i.e. aggregation decreased with increasing ionic strength (5-100 mM, Figure 3). In this case, aggregates were detected in spite of a significant negative electrostatic repulsion among the particles. In the absence of the SRFA, an increase in ionic strength is postulated to shield the charge of approaching particles and reduce the effectiveness of the Coulombic repulsion (leading to increased aggregation). In contrast, in the presence of $1.0 \mathrm{mg} \mathrm{L}^{-1}$ of SRFA, increasing ionic strength actually resulted in decreased aggregation at $\mathrm{pH}$ 8.0: at the highest ionic strength value $(0.1 \mathrm{M})$ the system was totally disaggregated (Figure 3). At $\mathrm{pH}$ 8.0, increased SRFA adsorption did not lead to significantly greater electrostatic repulsion (Figure 5) among the $\mathrm{TiO}_{2}$ nanoparticles. Furthermore, both the bare $\mathrm{TiO}_{2}$ nanoparticles (Figure 1b) and the fulvic acid (30) were negatively charged. Therefore, the increased stability of the nanoparticles at high ionic strength is attributed to a greater adsorption of the SRFA on the $\mathrm{TiO}_{2}$ resulting from the compression of the diffusive layer around both particles (i.e., $\mathrm{TiO}_{2}$ and SRFA). As discussed above, at $\mathrm{pH}$ 8.0, low SRFA concentrations appeared to induce aggregation due to increased bridging while the increased stabilization observed at higher concentrations (above $1.0 \mathrm{mg} \mathrm{L}^{-1}$ ) was attributed to steric effects. At the lower ionic strengths, increased intramolecular repulsion of the SRFA, leading to their increased molecular rigidity, is consistent with the observation of increased bridging flocculation (31). In contrast, the increased stability of the $\mathrm{TiO}_{2}$ nanoparticles that is observed in the presence of the SRFA at 
high ionic strengths is likely the result of increased steric stabilization of the particles $(7)$ in which the adsorption of the fulvic acid would increase the thickness of the steric barrier, thus preventing particle approach.

Clearly, particle charge alone (inferred from electrophoretic mobilities) was not a good indicator of particle stability: (i) ionic strength effects were relatively weak and (ii) in the presence of low concentrations of SRFA at $\mathrm{pH} 8.0$, the colloidal system was destabilized in spite of extremely negative values of electrophoretic mobility ( $c f$. Figure $1 \mathrm{~b}$ and Figure 4). In the literature, the role of humic substances on colloidal stability has often been attributed to an increased electrostatic repulsion following the adsorption of the humic substances (32), which does not appear to be the case here. The main difference between natural colloids that have been studied in the past and the $\mathrm{TiO}_{2}$ nanoparticles is their size; in this case, fulvic acid molecules (ca. $1.3-1.6 \mathrm{~nm}$, Figure 2$)$ are nearly the same size as the disaggregated $\mathrm{TiO}_{2}(c a$. 3$5 \mathrm{~nm}$, Figure 3) and for high ionic strengths are expected to exceed the double layer thickness. Indeed, for sterically stabilized systems much less of an ionic strength influence is expected or observed.

Along a similar line of reasoning, atomic force microscopy (AFM) has been used to show that the adsorption of $100 \mathrm{mg} \mathrm{L}^{-1}$ of SRFA on goethite particles $(d=5 \nabla \mathrm{m})$ resulted in a highly repulsive force at short separation distances (typically $<2$ to $3 \mathrm{~nm}$ ) (33) that could be attributed to increased steric forces. Based upon Figure 2, an adsorbed SRFA layer of approximately $5 \mathrm{~nm}$ (33) would correspond to a multilayer adsorption of SRFA or indeed the adsorption of SRFA aggregates. It is nonetheless noteworthy that relatively low surface 
coverage of the humic substances caused some destabilization of another iron oxide system (14).

\section{Environmental impact}

Clearly, in the natural environment, the fate, mobility, and bioavailability of nano$\mathrm{TiO}_{2}$ will be greatly influenced by particle size and charge. In this study, $\mathrm{TiO}_{2}$ nanoparticles were generally sterically stabilized in presence of fulvic acids, resulting in some disaggregation of small nanoparticle aggregates. These findings suggest that in the natural aquatic environment, the dispersion and mobility of $\mathrm{TiO}_{2}$ nanoparticles might occur to a much greater extent than predicted by laboratory measurements. Other parameters such as the nature of the natural organic matter, divalent ion contents and the size of the primary particles are also likely to play a critical role on the aggregation of the nanoparticles and will need to be examined in future studies.

It should be noted that particle sizes were also determined by dynamic light scattering but they were systematically much larger than those obtained by either FCS or TEM. Furthermore, the DLS result appeared to be typical of the light scattering literature. For example, for similar conditions to above $\left(2 \mathrm{mg} \mathrm{L}^{-1}\right.$ of the same $\left.\mathrm{TiO}_{2}, \mathrm{pH}=2, I=0.02 \mathrm{M}\right)$, Pettibone et al. (16) obtained a size of $c a .350 \mathrm{~nm}$ by dynamic light scattering. Since in dynamic light scattering the bias towards the large particle aggregates is much more important (scattering intensity $\propto d^{6}(34)$ ) than FCS, the z-average diameters obtained by light scattering might well be greatly overestimating actual particle sizes. This point will also be the object of a future paper. 


\section{Acknowledgments}

Funding for this work was provided by the Fundação para a Ciência e Tecnologia, Portugal

(Postdoctoral fellowship to RFD, SFRH/BPD/37731/2007), the Natural Sciences and

Engineering Research Council of Canada and the Fonds québécois de la recherche sur la nature et les technologies ( $F Q R N T)$. The authors appreciate the critical comments of three anonymous reviewers. 


\section{Supporting Information}

Some information on the theory behind FCS, a dynamic aggregation experiment and a TEM micrograph of the $\mathrm{TiO}_{2}$ are available in the supporting information. This information is available free of charge via the Internet at http://pubs.acs.org. 


\section{References}

(1) Wiesner, M. R.; Lowry, G. V.; Alvarez, P.; Dionysiou, D.; Biswas, P. Assessing the risks of manufactured nanomaterials. Environ. Sci. Technol. 2006, 40, 4336-4345.

(2) Kormann, C.; Bahnemann, D. W.; Hoffmann, M. R. Photolysis of chloroform and other organic molecules in aqueous $\mathrm{TiO}_{2}$ suspensions. Environ. Sci. Technol. 1991, 25, 494-500.

(3) Ohno, T.; Mitsui, T.; Matsumura, $\mathrm{M}_{\text {. }} \mathrm{TiO}_{2}$-photocatalyzed oxidation of adamantane in solutions containing oxygen or hydrogen peroxide. J. Photochem. Photobiol. A: Chemistry 2003, 160, 3-9.

(4) Chen, X.; Mao, S. S. Titanium dioxide nanomaterials: synthesis, properties, modifications, and applications. Chem. Rev. 2007, 107, 2891-2959.

(5) Tseng, Y. H.; Lin, H. Y.; Kuo, C. S.; Li, Y. Y.; Huang, C. P. Thermostability of nano-TiO 2 and its photocatalytic activity. React. Kinet. Catal. Lett. 2006, 89, 63-69.

(6) Grassian, V. H.; Adamcakova-Dodd, A.; Pettibone, J. M.; O'shaughnessy, P. T.; Thorne, P. S. Inflammatory response of mice to manufactured titanium dioxide nanoparticles: comparison of size effects through different exposure routes. Nanotoxicology 2007, 1, 211-226.

(7) Tipping, E.; Higgins, D. C. The effect of adsorbed humic substances on the colloid stability of heamatite particles. Colloids Surf. 1982, 5, 85-92.

(8) Wilkinson, K. J.; Reinhardt, A. In flocculation in natural and engineered environmental systems; CRC press: 2005.

(9) Brant, J.; Lecoanet, H.; Wiesner, M. R. Aggregation and deposition characteristics of fullerene nanoparticles in aqueous systems. J. Nanoparticle Res. 2005, 7, 545-553.

(10) Chen, K. L.; Elimelech, M. Influence of humic acid on the aggregation kinetics of fullerene $\left(\mathrm{C}_{60}\right)$ nanoparticles in monovalent and divalent electrolyte solutions. J. Colloid Interface Sci. 2007, 309, 126134.

(11) Hyung, H.; Fortner, J. D.; Hughes, J. B.; Kim, J. H. Natural organic matter stabilizes carbon nanotubes in the aqueous phase. Environ. Sci. Technol. 2007, 41, 179-184.

(12) Chen, K. L.; Mylon, S. E.; Elimelech, M. Aggregation kinetics of alginate-coated hematite nanoparticles in monovalent and divalent electrolytes. Environ. Sci. Technol. 2006, 40, 1516-1523.

(13) Tipping, E.; Ohnstad, M. Colloid stability of iron oxide particles from a freshwater lake. Nature 1984, 308, 266-268.

(14) Illés, E.; Tombácz, E. The effect of humic acid on $\mathrm{pH}$-dependent surface charging and aggregation of magnetite nanoparticles. J. Colloid Interface Sci. 2006, 295, 115-123.

(15) Guzman, K. A. D.; Finnegan, M. P.; Banfield, J. F. Influence of Surface Potential on Aggregation and Transport of Titania Nanoparticles. Environ. Sci. Technol. 2006, 40, 7688-7693.

(16) Pettibone, J. M.; Cwiertny, D. M.; Scherer, M.; Grassian, V. H. Adsorption of organic acids on $\mathrm{TiO}_{2}$ nanoparticles: effects of $\mathrm{pH}$, nanoparticle size, and nanoparticle aggregation. Langmuir 2008, 24, 6659-6667.

(17) Elson, E. L.; Magde, D. Fluorescence correlation spectroscopy. I. Conceptual basis and theory. Biopolym. 1974, 13, 1-27.

(18) Starchev, K.; Zhang, J.; Buffle, J. Applications of fluorescence correlation spectroscopy - particle size effect. J. Colloid Interface Sci. 1998, 203, 189-196.

(19) Gendron, P.-O.; Avaltroni, F.; Wilkinson, K. J. Diffusion coefficients of several rhodamine derivatives as determined by pulsed field gradient-nuclear magnetic resonance and fluorescence correlation spectroscopy. J. of Fluorescence 2008 in press. 
(20) Starchev, K.; Wilkinson, K. J.; Buffle, J. Application of Fluorescence Correlation Spectroscopy to the Study of Environmental Systems In Fluorescence Correlation Spectroscopy: Theory and Applications; Springer: Heidelberg, 2000.

(21) Widengren, J.; Mets, U.; Rigler, R. Fluorescence correlation spectroscopy of triplet states in solution: a theoretical and experimental study. J. Phys. Chem. 1995, 99, 13368-13379.

(22) Kormann, C.; Bahnemann, D. W.; Hoffmann, M. R. Preparation and characterization of quantum-size titanium dioxide. J. Phys. Chem. 1988, 92, 5196-5201.

(23) Jing, C.; Meng, X.; Liu, S.; Baidas, S.; Patrajn, R.; Christodoulatos, C.; Korfiatis, G. P. Surface complexation of organic arsenic on nanocrystalline titanium oxide. J. Colloid Interface Sci. 2005, 290, 14-21.

(24) Pena, M. E.; Korfiatis, G. P.; Patel, M.; Lippincott, L.; Meng, X. Adsorption of As(V) and As(III) by nanocrystalline titanium dioxide. Water Res. 2005, 39, 2327-2337.

(25) Pena, M. E.; Meng, X.; Korfiatis, G. P.; Jing, C. Adsorption mechanism of arsenic on nanocrystalline titanium dioxide. Environ. Sci. Technol. 2006, 40, 1257-1262.

(26) Lead, J. R.; Wilkinson, K. J.; Starchev, K.; Canonica, S.; Buffle, J. Determination of diffusion coefficients of humic substances by fluorescence correlation spectroscopy: role of solution conditions. Environ. Sci. Technol. 2000, 34, 1365-1369.

(27) Avena, M. J.; Vermeer, A. W. P.; Koopal, L. K. Volume and structure of humic acids studied by viscometry: $\mathrm{pH}$ and electrolyte concentration effects. Colloids and Surfaces A: Physicochem. Eng. Aspects 1999, 151, 213-224.

(28) Balnois, E.; Wilkinson, K. J.; Lead, J.; Buffle, J. Atomic force microscopy study of humic substances adsorbed on mica surfaces: effects of $\mathrm{pH}$ and ionic strength. Environ. Sci. Technol. 1999, 33, 3911-3917.

(29) Lead, J. R.; Wilkinson, K. J.; Balnois, W.; Cutak, B. J.; Larive, C. K.; Assemi, S.; Beckett, R. Diffusion coefficients and polydispersities of the Suwannee River Fulvic Acid: comparison of fluorescence correlation spectroscopy, pulsed-field gradient nuclear magnetic resonance, and flow fieldflow fractionation. Environ. Sci. Technol. 2000, 34, 3508-3513.

(30) Hosse, M.; Wilkinson, K. J. Determination of electrophoretic mobilities and hydrodynamic radii of three humic substances as a function of $\mathrm{pH}$ and ionic strength. Environ. Sci. Technol. 2001, 35, 4301-4306.

(31) Buffle, J.; Wilkinson, K. J.; Stoll, S.; Filella, M.; Zhang, J. A generalized description of aquatic colloidal interactions: the three-colloidal component approach. Environ. Sci. Technol. 1998, 32, $2887-$ 2899.

(32) Wilkinson, K. J.; Negre, J. C.; Buffle, J. Coagulation of colloidal material in surface waters: the role of natural organic matter. J. Contaminant Hydrology 1997, 26, 229-243.

(33) Assemi, S.; Hartley, P. G.; Scales, P. J.; Beckett, R. Investigation of adsorbed humic substances using atomic force microscopy. Colloids and Surfaces A: Physicochem. Eng. Aspects 2004, 248, 17-23.

(34) Schurtenberger, P.; Newman, M. E. In Environmental Particles - Characterization of biological and environmental particles using static and dynamic light scattering, Buffle, J.; van Leeuwen, H. P., Eds.; Lewis: 1993; Vol. II, pp 37-115. 


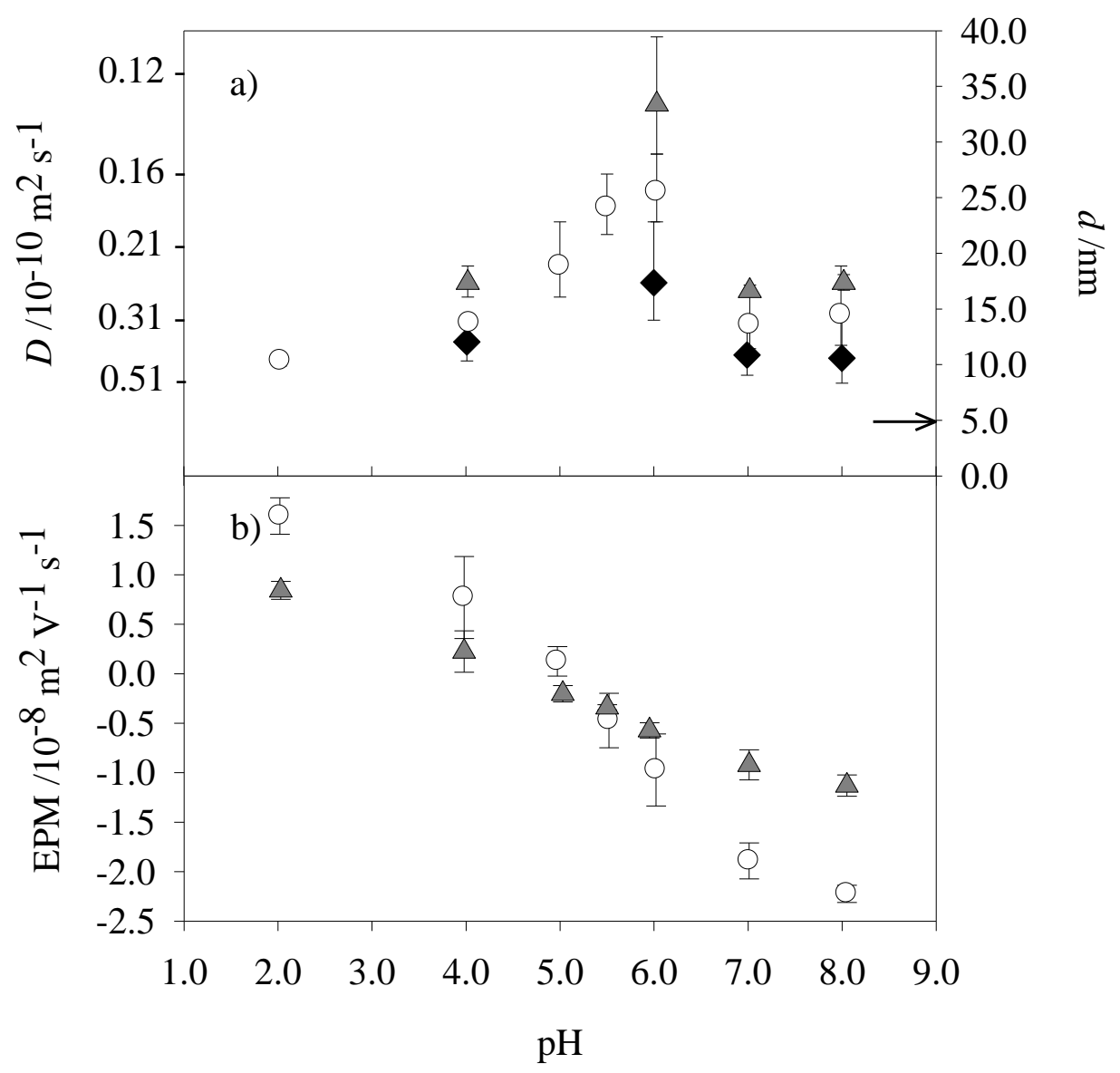

Figure $1-$ a) Variation of the diffusion coefficients and weight average diameters of the bare (R6G labelled) $1.0 \mathrm{mg} \mathrm{L}^{-1} \mathrm{TiO}_{2}$ nanoparticles as function of $\mathrm{pH}$ for three ionic strengths: $0.005 \mathrm{M}(\bullet), 0.01 \mathrm{M}(\bigcirc)$ and $0.1 \mathrm{M}(\mathbf{\Delta})$. b) Electrophoretic mobilities of the bare $1.0 \mathrm{mg}$ $\mathrm{L}^{-1} \mathrm{TiO}_{2}$ nanoparticles as a function of $\mathrm{pH}$ at two ionic strengths: $0.01 \mathrm{M}(\mathrm{O})$ and $0.1 \mathrm{M}(\Delta)$. The arrow in Figure 1a indicates the size of the disaggregated $\mathrm{TiO}_{2}$ nanoparticles given by NanoAmor. 


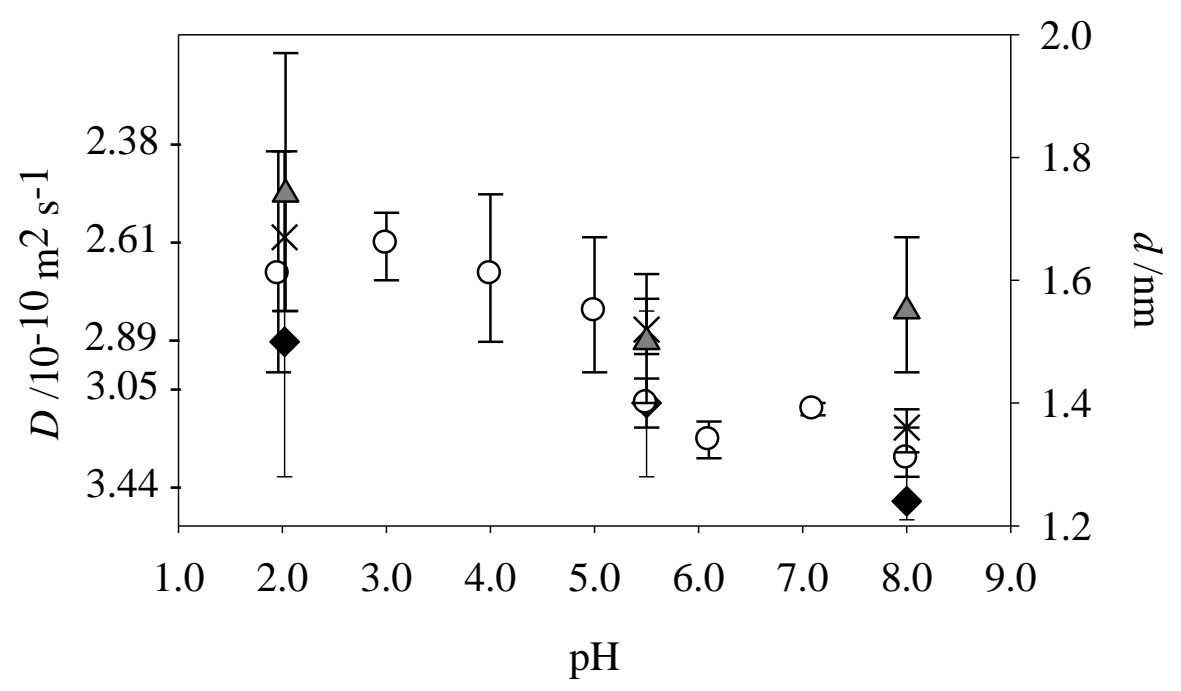

Figure 2 - Variation of diffusion coefficients and weight average diameters of $1 \mathrm{mg} \mathrm{L}^{-1}$ of Suwannee River fulvic acid for four ionic strengths: $0.005 \mathrm{M}(\diamond), 0.01 \mathrm{M}(\bigcirc), 0.05 \mathrm{M}(*)$ and $0.1 \mathrm{M}(\mathbf{\Delta})$. 


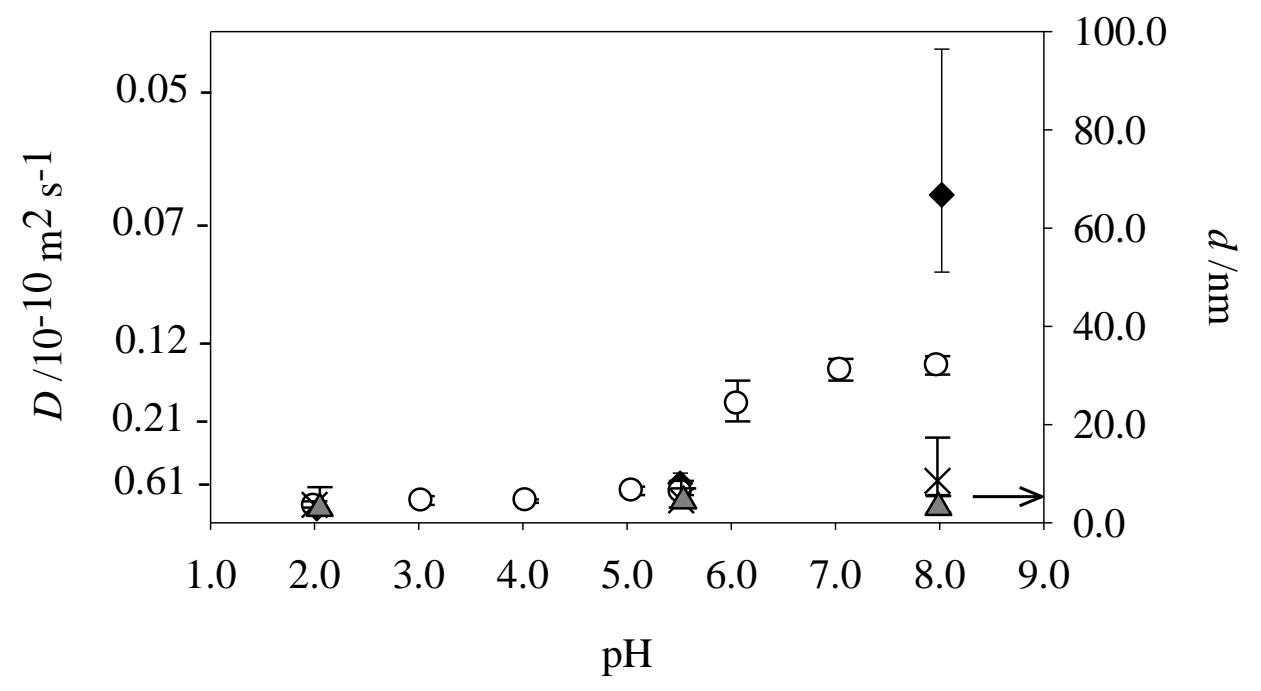

Figure 3 - Variation of diffusion coefficients and weight average diameters of $1.0 \mathrm{mg} \mathrm{L}^{-1}$ of $\mathrm{TiO}_{2}$ nanoparticles in presence of $1.0 \mathrm{mg} \mathrm{L}^{-1}$ of SRFA as a function of $\mathrm{pH}$ for four ionic strengths: $0.005 \mathrm{M}(\diamond), 0.01 \mathrm{M}(\bigcirc), 0.05 \mathrm{M}(*)$ and $0.1 \mathrm{M}(\Delta)$. The arrow indicates the size of the disaggregated $\mathrm{TiO}_{2}$ nanoparticles given by NanoAmor. 


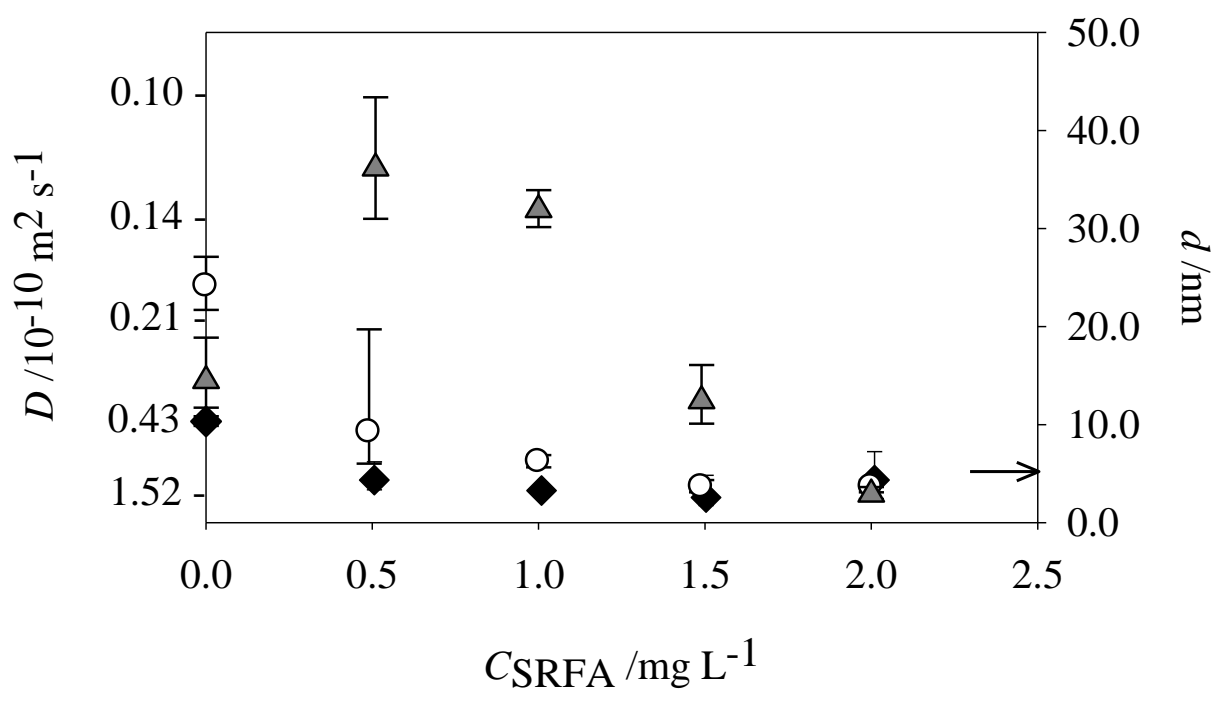

Figure 4 - Variation of diffusion coefficients and weight average diameters of $1.0 \mathrm{mg} \mathrm{L}^{-1}$ of $\mathrm{TiO}_{2}$ nanoparticles as a function of the concentration of SRFA for an ionic strength of 0.01 $\mathrm{M}$ and for three different pH values: $2.0(\diamond), 5.5(\mathrm{O})$ and $8.0(\Delta)$. The arrow indicates the size of the disaggregated $\mathrm{TiO}_{2}$ nanoparticles given by NanoAmor. 


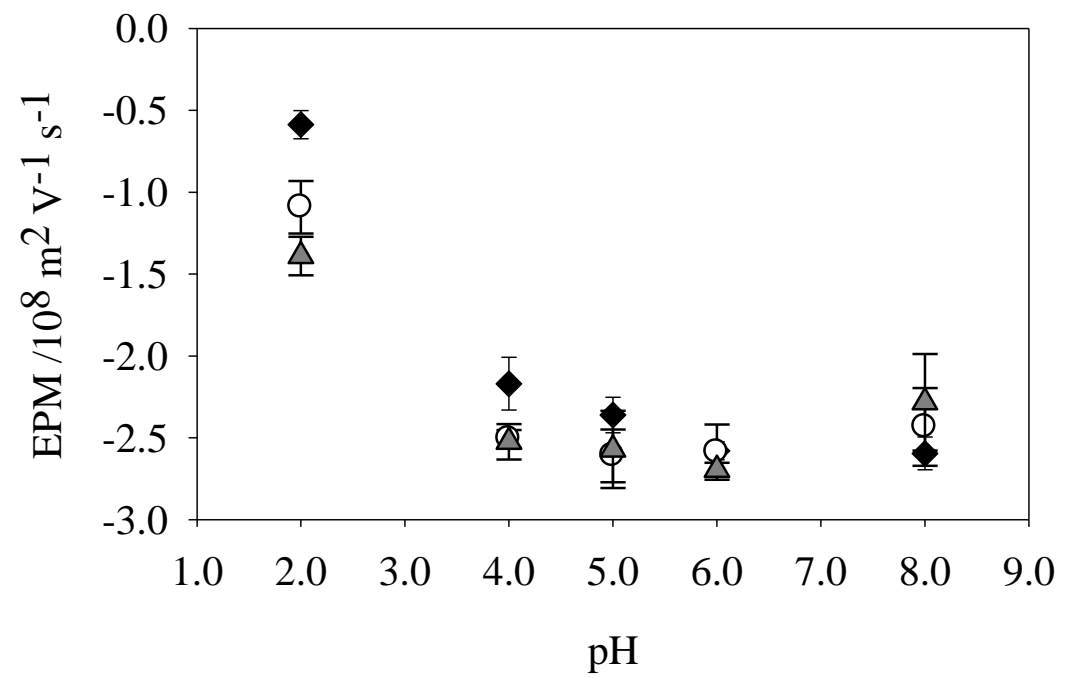

Figure 5 - Electrophoretic mobilities of $1.0 \mathrm{mg} \mathrm{L}^{-1}$ of $\mathrm{TiO}_{2}$ nanoparticles as a function of $\mathrm{pH}$ for an ionic strength of $0.01 \mathrm{M}$ and different SRFA concentrations: $1.0 \mathrm{mg} \mathrm{L}^{-1}(\diamond), 2.0 \mathrm{mg} \mathrm{L}-$ ${ }^{1}(\mathrm{O}), 5.0 \mathrm{mg} \mathrm{L}^{-1}(\Delta)$. 


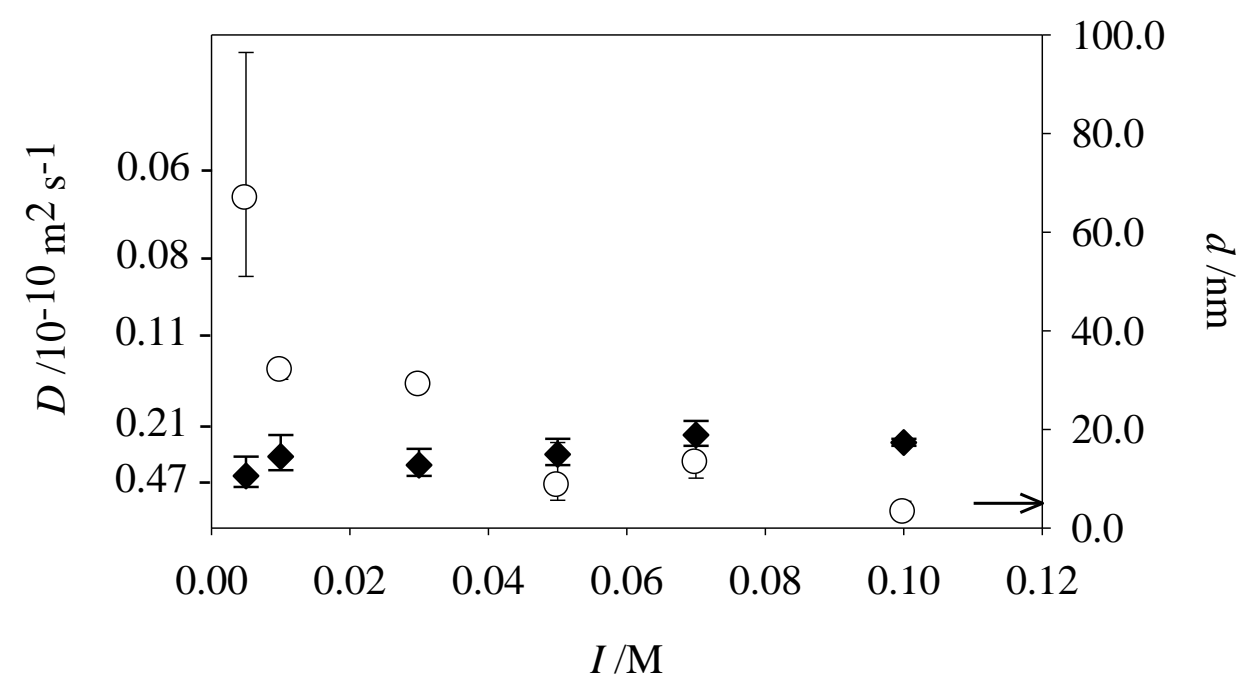

Figure 6 - Variation of the diffusion coefficient and weight average diameter of $1.0 \mathrm{mg} \mathrm{L}^{-1}$ of $\mathrm{TiO}_{2}$ nanoparticles as a function of ionic strength at $\mathrm{pH} 8.0$ in the absence $(\bullet)$ and presence (O) of $1.0 \mathrm{mg} \mathrm{L}^{-1} \mathrm{SRFA}$. The arrow indicates the size of the disaggregated $\mathrm{TiO}_{2}$ nanoparticles given by NanoAmor. 


\section{Brief}

The stability of $\mathrm{TiO}_{2}$ nanoparticles is evaluated for $0.2-5.0 \mathrm{mg} \mathrm{L} \mathrm{L}^{-1}$ of Suwannee River Fulvic Acid, $\mathrm{pH} 2-8$, ionic strength $0.005-0.1 \mathrm{M}$. 